Western University Scholarship@Western

Centre for the Study of International Economic

Centre for the Study of International Economic

Relations Working Papers

Relations

1980

\title{
Trade and the Gains from Trade with Imperfect Competition
}

James R. Markusen

Follow this and additional works at: https://ir.lib.uwo.ca/economicscsier_wp

Part of the Economics Commons

Citation of this paper:

Markusen, James R.. "Trade and the Gains from Trade with Imperfect Competition." Centre for the Study of International Economic Relations Working Papers, 8007. London, ON: Department of Economics, University of Western Ontario (1980). 
CENTRE FOR THE STUDY OF INTERNATIONAL ECONOMIC RELATIONS

WORKING PAPER NO. 8007

TRADE AND THE GAINS FROM TRADE WITH IMPEREECT COMPETITION

James R. Markusen

This paper contains preliminary findings from research still in progress and should not be quoted without prior approval of the author.

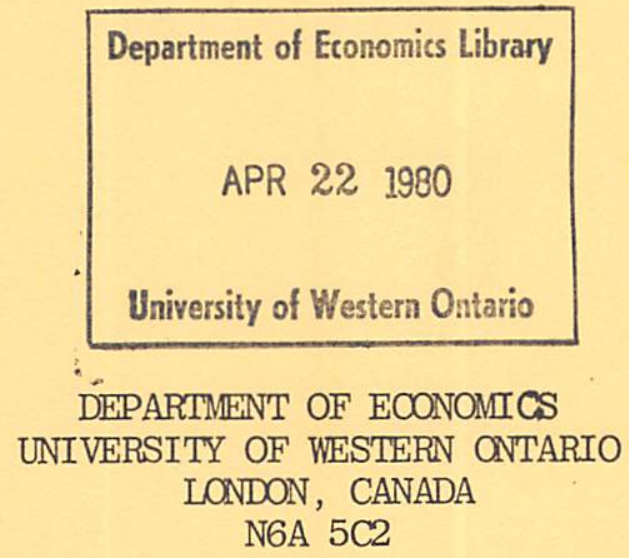


TRADE AND THE GAINS FROM TRADE

WITH IMPERFECT COMPETITION

\author{
James R. Markusen \\ Department of Economics \\ University of Western Ontario \\ London \\ Canada
}

\begin{abstract}
A simple two-country model is constructed in order to show how imperfect competition can form a basis for trade. Under the assumption of Cournot-Nash behavior, it is demonstrated that trade will lead to a bilateral welfare improvement when countries are identical in all respects. When countries differ in size, trade will always increase total world real income, but the large country may experience a welfare loss. Increasing returns to scale in the production of the monopolized good complicates the situation further, but it generally remains true that trade increases world real income.
\end{abstract}

First Draft

February, 1980 


\section{Introduction}

It is probably fair to say that international trade economists have long recognized the importance of imperfect competition and increasing returns to scale in determining both the direction of and gains from trade. Both of these factors are given important roles by such distinguished economists as Frank Graham (1923), Bertil Ohlin (1933), and Charles Kindleberger (1969). Much more recently, trade theorists have begun to construct formal models of imperfect competition and increasing returns to scale in order to sort out the precise circumstances under which the propositions of earlier writers are or are not valid.

The role of IRS as a determinant of trade has, for example, been recently examined by Melvin (1969), Ethier (1979), Krugman (1979), and Markusen and Melvin (1980). Among other things, these authors show that increasing returns imply that there will often exist gains from trade even if two countries are absolutely identical in all respects. More specifically, trade under conditions of increasing returns may permit cost savings through increased specialization even though there does not exist any natural pattern of comparative advantage.

Considerably less well developed is a growing literature on general equilibrium and trade under conditions of imperfect competition. Negishi (1961) and Krugman (1979) adopt monopolistic competition models in which firms with decreasing average cost produce differentiated goods. Krugman points out that trade will allow the production of more types of goods, resulting in gains from trade even for two identical economies. Melvin and Warne (1973) consider the case of pure monopoly, and derive necessary and sufficient conditions for 
the existence of a monopoly equilibrium. Melvin and Warne also discuss the question of gains from trade, but are able to derive very few firm results. They discuss the possibility of one or even both countries losing from trade, but do not prove that any of these situations can or cannot occur.

The purpose of the present paper is to offer a number of extensions to the basic theory for the case of pure monopoly. The paper will, in particular, extend and in some cases reverse several propositions put forward by Melvin and Warne. In order to accomplish this purpose, section II develops a two-good, two-factor, two-country model in which the production of one good is monopolized in both countries (i.e., the same sector is monopolized in each country). The monopolist in each country is assumed to behave in a Cournot-Nash fashion when trade takes place.

The first contribution of the paper is to note that if both countries are identical in all respects, there will in fact exist bilateral gains from trade given the Cournot-Nash assumption. Interestingly, trade will not occur when both identical economies are open unless there are increasing returns in production. The presence of potential competition, however, implies that the two Cournot duopolists will each produce more than in the absence of trade possibilities, thus leading to an improvement in welfare. Imperfect competition can therefore lead to gains from trade for two identical economies. This finding is similar to and indeed complimentary to the point made by Melvin (1969) and Krugman (1979) about gains from trade under conditions of increasing returns.

When countries differ in size, and when there are constant returns to scale in production, it is demonstrated that the Cournot-Nash equilibrium 
involves the large country importing the monopolized good. With constant returns, total world real income is always increased by trade, a finding that Melvin and Warne were not able to prove. The distribution of gains will, however, be unequal if country sizes are unequal. The small country w111 always be an absolute and a relative gainer, while the large country may in fact lose relative to autarky. A sufficient condition for the large country to gain is that trade lead to an expansion in the domestic production of the monopolized good. One final result for the different-country-size, constant-returns case is that trade may make relative factor prices more unequal in the two countries relative to autarky. ${ }^{2}$

The final section of the paper considers briefly the more complicated case of increasing returns in the production of the monopolized good. With increasing returns to scale, the large country has a cost advantage in producing and exporting the monopolized good. This cost-side condition thus tends to work in the opposite direction to the demand-side condition just mentioned. This unfortunately leaves us with a Cournot-Nash equilibrium in which both the direction of trade and the distribution of gains from trade are indeterminant. Trade is still guaranteed to increase total world real income, however, provided that the production set of each country is convex. 
II. Cournot-Nash Equilibrium: The Constant-Returns-to-Scale Case

Two countrles (country $L$ and country S) produce and trade two goods ( $X$ and $Y$ ) from factors in flxed and inelastic supply. Superscripts $l$ and $s$ will denote country $I$ and country S respectively. In each country, $X$ is produced by a monopolist who owns no factors of production while $Y$ is produced competitively. The monopolist in other words, only owns "property rights" to the production of $X$. $P$ will denote the price of $X$ in terms of $Y\left(p=p_{X} / p_{y}\right)$. In order to focus on the output market distortion, we will assume that factor markets are competitive. Thus the monopolist views himself as being able to influence the price of $X$ but not the prices of factors of production. This could occur, for example, if $X$ is a small percentage of national output. Adding the assumption of monopsony power (Herberg and Kemp (1971), Markarsen and Robson (1980)) would significantly complicate the analysis via distortions in the production frontier but would not, in my opinion, add to or alter the results in any substantial way.

Given this factor-market assumption, we have of course the standard result that production w111 be efficient and that it will take place at a point on the efficlent production frontier. This production frontier, or production possibility curve, will be specified as follows:

$$
\begin{aligned}
& \text { (1) } \mathrm{Y}^{1}=\mathrm{F}^{1}\left(\mathrm{X}^{1}\right) \quad \mathrm{F}^{1^{\prime}}\left(\mathrm{X}^{1}\right)<0 \\
& -\mathrm{F}^{\mathrm{i}^{\prime}}=\mathrm{MC}_{\mathrm{x}}^{1} / \mathrm{MC}_{\mathrm{y}}^{i}=\mathrm{MRT}^{i} \\
& 1=\ell, 8,
\end{aligned}
$$

where $\mathrm{MC}_{X}$ and $M C_{y}$ are respectively the marginal costs of $X$ and $Y$ and $M R T$ is the marginal rate of transformation, defined to be positive. Throughout this section, we will assume constant returns to scale and differing factor 
Intensities between goods such that $F^{\prime \prime}<0$; that is, the production possibility curve is concave (the production set is convex). A second very useful result that follows from constant returns is that the MRT depends only on the ratio $\mathrm{Y}^{1} / \mathrm{X}^{1}$ if two countries have identical relative factor endowments. Thus if $X$ and $Y$ are produced from capital and labour ( $K$ and $L$ ), for example, we have the following result:

$$
\overline{\mathrm{K}} l / \overline{\mathrm{L}}{ }^{\ell}=\overline{\mathrm{K}^{8}} / \overline{\mathrm{L}^{8}} \text { implies } \mathrm{F}^{\ell^{\prime}}=\mathrm{F}^{8^{\prime}} \Leftrightarrow \mathrm{F}^{\ell} / \mathrm{X}^{\ell}=\mathrm{Y}^{8} / \mathrm{X}^{8}
$$

where $\vec{K}^{\mathcal{L}}$ and $\overrightarrow{\mathrm{L}}^{\mathfrak{1}}$ are country $\mathcal{I}^{\prime} \mathrm{s}$ total endowments of capital and labour respectively. Throughout the paper, we will assume that endowment ratios are equal so as to "neutralize" the Heckscher-Ohlin basis for trade.

On the demand side of the model, it is assumed that all consumers, including the two duopolists, have identical and homothetic utility functions. Second, it is assumed that the duopolists maximize profits in their roles as producers, rather than maximize the utility of their consumption bundles (see Markusen (1980)).

Under these assumptions, the equilibrium condition for a closed economy (i.e., the autarky equilibrium condition) follows from Markusen. (3) $\quad \mathrm{MRT}=\mathrm{p}\left(1-1 / \eta_{\mathrm{x}}\right)<\mathrm{p}=\mathrm{MRS}$

where $\eta$. is the elasticity of demand for $X$ and MRS is the consumer's marginal rate of substitution. Such an equilibrium is shown in Figure $I$ by point $A$, where MRT $<$ MRS

Little more can be said without making more specific assumptions about the utility functions. The reason for this is that the properties of $\eta_{x}$ depend entirely on the properties of the preference functions. Thus for the remainder of the paper, we will assume that community preferences in each country can be represented by a C.E.S. utility function of the following form. 


\section{FIGURE I}

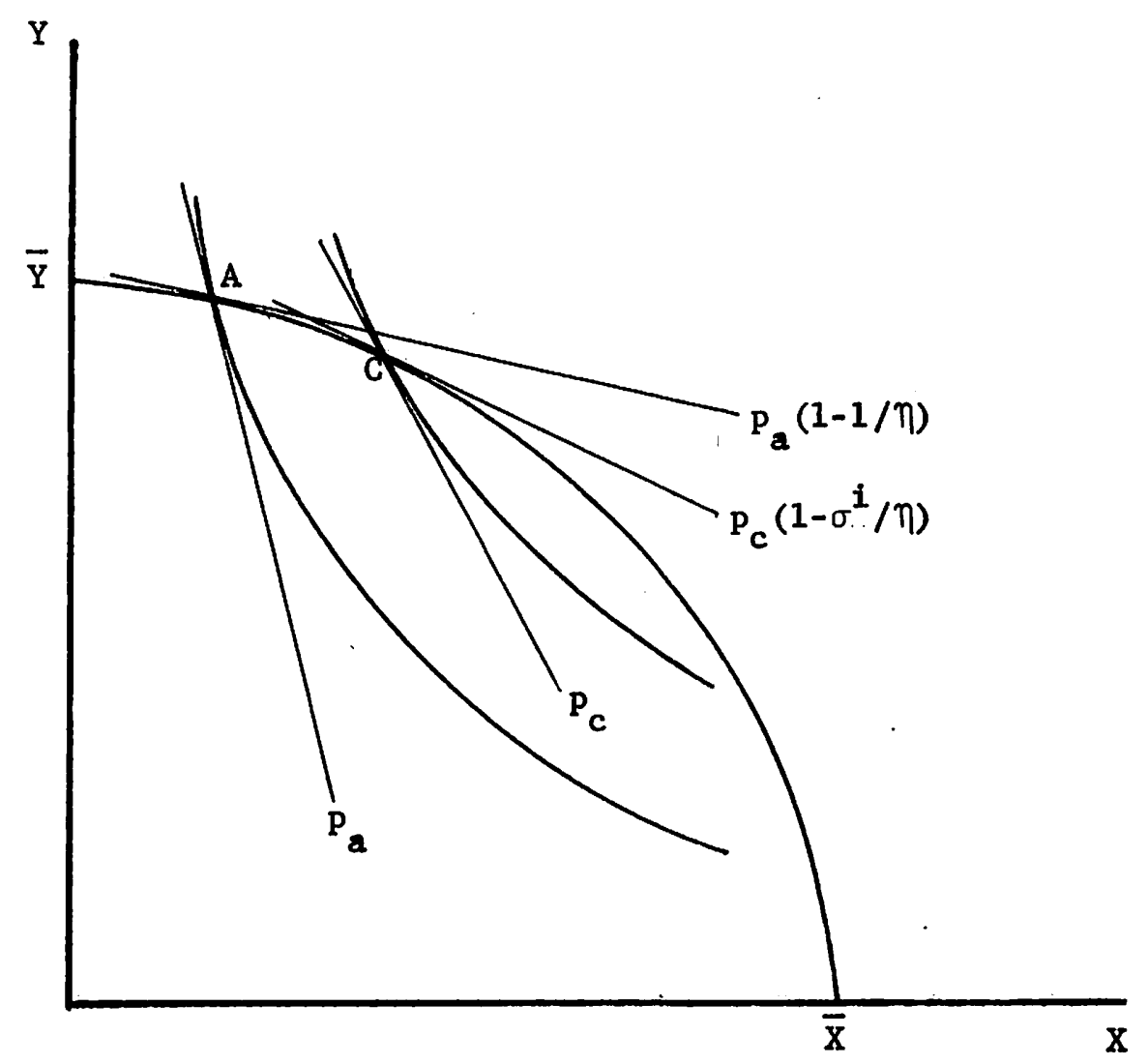

FIGURE II

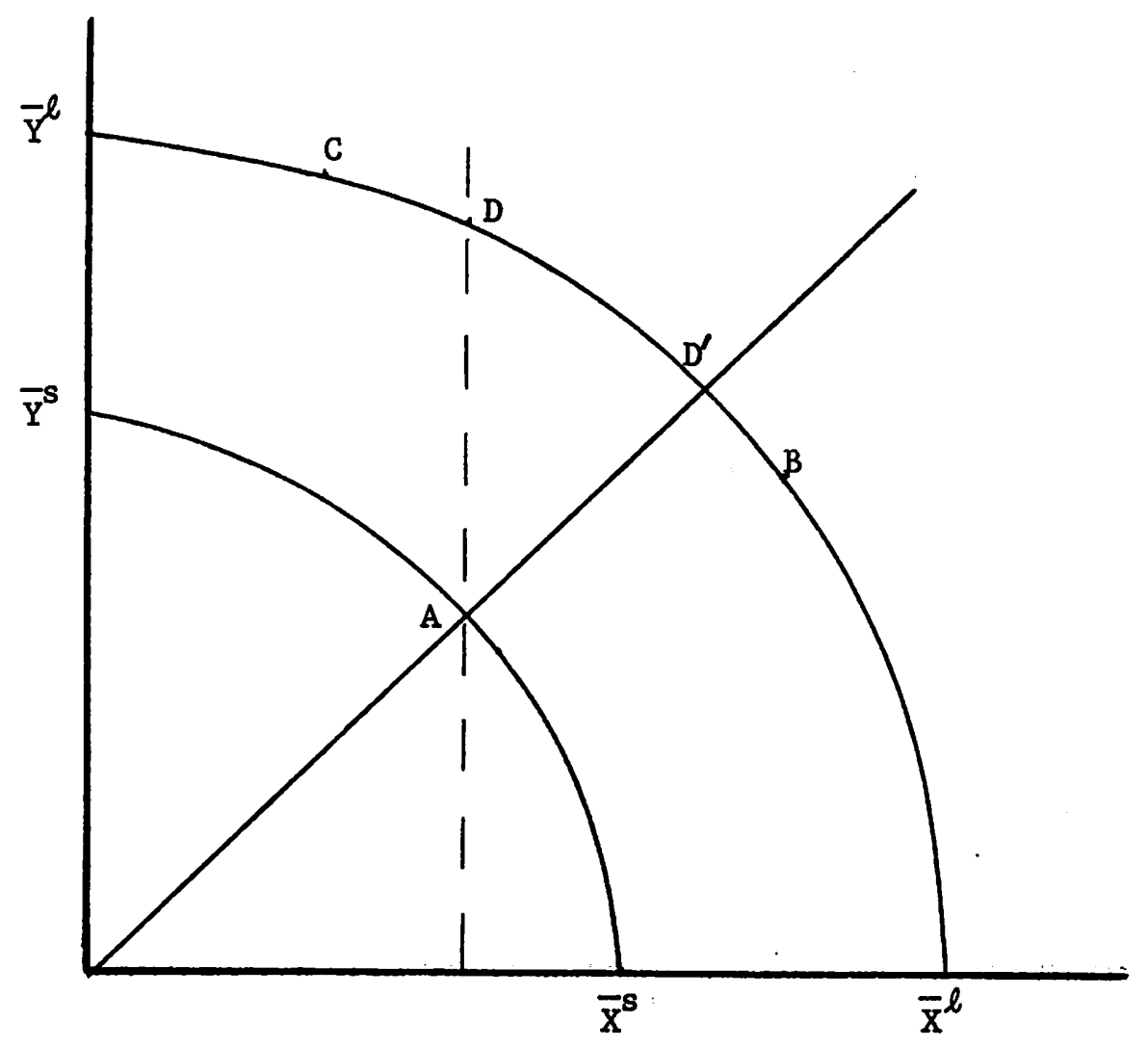


(4) $\quad U=\left(a X^{-\beta}+b Y^{-\beta}\right)^{-1 / \beta} ;-1<\beta<\infty, \sigma=\frac{1}{1+\beta}$.

Values of $\beta$ less than zero correspond to elasticities of substitution greater than 1 and vice versa.

Denoting community income in terms of $Y$ as $I$, (4) can be maximized subject to I to yield a demand function for $X$.

$$
X=\frac{I}{p\left[1+(b / a)^{1 /(\beta+1)} p^{-\beta /(\beta+1)}\right]}=\frac{I}{p\left(1+\alpha_{p}^{\sigma_{p}^{-\beta \sigma}}\right)}
$$

where $\alpha=(b / a)$ and $I=p X+Y$.

Elsewhere (Markusen (1980)) I have demonstrated that with homothetic demand it is immaterlal whether the monopolist views total income as fixed or varlable. Demand elasticities depend only on relative outputs and not on income. Denoting the monopolist's costs in terms of $Y$ as $C(X)$, we can therefore represent each monopol18t's closed economy problem as follows:

(6) $\operatorname{Max} p X-c(x)$ S.T. $\left.x=\frac{\bar{I}}{p\left(1+\alpha^{\sigma}-\beta \sigma\right.}\right)$

Equation (5) can be rearranged as follows:

(7) $\quad \mathrm{Xp}\left(1+\alpha^{\sigma}{ }^{-\beta \sigma}\right)=\mathrm{X}\left(\mathrm{p}+\alpha^{\sigma} \mathrm{p}^{1-\beta \sigma}\right)=\overline{\mathrm{I}}$.

Differentiating with respect to $\mathrm{p}$ and $\mathrm{X}$ gives us

$$
x\left(1+\alpha^{\sigma}(1-\beta \sigma) p^{-\beta \sigma}\right) \frac{d p}{d x}+\left(p+\alpha^{\sigma} p^{1-\beta \sigma}\right)=0
$$

We can then solve for $d p / d X$ and multiply through by $x / p$ to get the elasticity of demand.

$$
\frac{1}{\eta_{x}}=-\frac{x}{p} \frac{d p}{d x}=\frac{\left(1+\alpha^{\sigma} p^{-\beta \sigma}\right)}{\left(1+\alpha^{\sigma}(1-\beta \sigma) p^{-\beta \sigma}\right)}<1 \text { iff }\left\{\begin{array}{l}
\beta<0 \\
\sigma>1
\end{array}\right.
$$


As noted in (9), values of $\eta_{x}$ less than 1 only exist if the elasticity of substitution exceeds 1. Thus it is clear from (9) that a solution to (3) exists only for values of $\sigma$ greater than 1 . Th1s result was derived by Melvin and Warne and requires us to restrict the range of functions under consideration to those having $\sigma>1(\beta<0)$. Proof of the existence and uniqueness of a solution for all values of $\beta$ between -1 and 0 is straightforward and analyzed in detail by Melvin and Warne and by Markusen. It is sufficient for our purposes to note that $1 / \eta_{\mathrm{x}}$ increases monotonically with the ratio of $\mathrm{X}$ to $\mathrm{Y}$ $(X / Y)$ In consumption given the restriction that $\beta<0$. Since $p$ (the consumer price ratio) decreases monotonically with $X / Y$, this in turn implies that $p\left(1-1 / \eta_{X}\right)$ falls monotonically with $X / Y \cdot p\left(1-1 / \eta_{X}\right)$ approaches infinity as $X / Y$ approaches zero ( $1 . e_{1}$, as we approach the $\mathrm{Y}$-axis end of the production frontier) and approaches zero as $X / Y$ approaches infinity. Given these results, the autarky equilibria are very simply given as follows:

$$
\mathrm{p}^{1}\left(1-1 / \eta_{x}^{1}\right)=-\mathrm{F}^{\prime}\left(\mathrm{x}^{1}\right) \quad 1=\ell, 8
$$

since $C^{\prime}(X)=-F^{\prime}(X)$ In the absence of factor market distortions. What I wish to emphasize here is that if (A) there are constant returns and identical relative factor endowments in the two countries such that equation (2) holds, and If (B) all consumers have identical and homothetic tastes as assumed above, then the solution to (10) is the same for each country. In autarky, the two countries would have identical price ratios.

According to classical trade theory, Identical autarky price ratios generally preclude gains from trade. This is not the case in the present formulation. Suppose that we open the two economies to trade, and that the monopolist in each country behaves in a Cournot-Nash fashion. More specifically, each monopolist behaves as though his rival's output is fixed and unresponsive. Algebraically, the monopolist in country $L$ for example 
confronts the following problem

(11) $\quad \operatorname{Max} \mathrm{px}^{\ell}+\mathrm{c}^{\ell}\left(\mathrm{x}^{\ell}\right)$ s.T. $\quad \mathrm{x}^{\ell}+\overline{\mathrm{x}}^{8}=\frac{\overline{I^{\ell}+} \overline{I^{8}}}{\mathrm{p}\left(1+\alpha_{\mathrm{p}}^{\sigma^{-\beta \sigma}}\right)}$

$p$ now denotes the world price of $X$ in terms of $Y$ and $\vec{X}^{3}$ denotes the cournotNash assumption that $x^{8}$ is assumed fixed. The elasticity of total world demand is now given by

$$
\frac{1}{\eta_{x}}=-\frac{\left(x^{\ell}+x^{8}\right)}{p} \frac{d p}{d x}=\frac{1+\alpha^{\sigma}-\beta \sigma}{1+\alpha^{\sigma}(1-\beta \sigma) p^{-\beta \sigma}}
$$

Multiplying (12) through by $x^{\ell} /\left(x^{\ell}+x^{8}\right)$ gives the elasticity of demand as viewed by the monopolist in country $L$.

$$
\begin{aligned}
& \frac{\sigma^{l}}{\eta_{x}}=-\frac{x^{l} d p}{p d x}=\frac{1+\alpha_{p}^{\sigma} p^{-\beta \sigma}}{1+\alpha^{\sigma}(1-\beta \sigma) p^{-\beta \sigma}} \cdot \frac{x^{\ell}}{x^{l}+x^{s}} \\
& \sigma^{l}=x^{l} /\left(x^{l}+x^{s}\right) .
\end{aligned}
$$

$\sigma^{l}$ is thus country $l^{\prime} s$ market share of total world production of $x .^{3}$ The equilibrium conditions for Cournot equilibrium which correspond to the autarky conditions given in (10) are given as follows,

$$
\mathrm{p}^{i}\left(1-\sigma^{i} / \eta_{\mathrm{x}}\right)=-\mathrm{F}^{i^{\prime}}\left(\mathrm{x}^{i}\right) \quad i=\ell, \mathrm{s} .
$$

Presuming that there are no tariffs or transport costs which would make prices unequal between countries, equation (14) implies a very simple relationship.

$$
\sigma^{l}>\sigma^{s} \Leftrightarrow-F^{\ell^{\prime}}\left(x^{l}\right)<-F^{s}\left(x^{s}\right) \text {. }
$$

Given constant returns and identical endowment ratios as assumed in equation (2), we also have

(16) $\sigma^{l}>\sigma^{s} \Leftrightarrow-F^{l^{\prime}}\left(X^{l}\right)<-F^{s^{\prime}}\left(x^{s}\right) \Leftrightarrow X^{l} / Y^{l}<X^{s} / Y^{s}$. 
Consider first the case where both countries are of identical size such that both of their identical production frontiers are represented by $\overline{Y X}$ in Figure I. In this special case, the opening of the two economies to trade will not actually cause trade, but will lead to an expansion in the production of $X$ in each country as shown by the movement from $A$ to $C$ in Figure I.

This result can be demonstrated using equations (14) and (16). Note first from (14) that point $A$ in Figure I can no longer be an equilibrium. With the opening of trade, $\sigma^{i}$ falls from one to one-half, thus giving the monopolist in each country the incentive to expand production. Suppose at the new equilibrium, $x^{l}$ exceeds $x^{s}$. This implies that $\sigma^{l}>\sigma^{s}$ but also that $\mathrm{X}^{\ell} / \mathrm{Y}^{\ell}>\mathrm{X}^{s} / \mathrm{Y}^{s}$ by virtue of the fact that the two countries are identical. This violates equation (16), however. A similar arguement shows that $\mathrm{x}^{\mathrm{s}}$ cannot exceed $x^{\ell}$, and thus it must be the case that $x^{s}=x^{\ell}$. Equation (14) in turn assures us that the open economy equilibrium must be to the right of $A$ in Figure I at a point like $C$. This Cournot equilibrium involves no trade (consumer prices are equalized without trade) but does involve an unambiguous gain in welfare relative to autarky.

Differences in country size can be analyzed with the help of Figure II, where $\overline{\mathrm{Y}}^{l} \overline{\mathrm{X}}^{\ell}$ and $\overline{\mathrm{Y}} \mathrm{\textrm {X }} \overline{\mathrm{S}}$ are the production frontiers of countries $\mathrm{L}$ and $\mathrm{S}$ respectively. Once again, we continue to assume that relative factor endowment ratios are equal such that equation (2) holds. Suppose that point A in Figure II is the open-economy, Cournot equilibrium for country S. Point B in Figure II cannot be the corresponding equilibrium for country $L$, because a comparison of $A$ and $B$ shows that $\sigma^{l}>\sigma^{s}$ but $-F^{\ell^{\prime}}\left(X^{l}\right)>-F^{s}\left(X^{s}\right)$, which violates equation (16). Similarly point $C$ in Figure II cannot be the equilibrium for country $L$ since $\sigma^{l}<\sigma^{s}$ and $-F^{l^{\prime}}\left(X^{l}\right)<-F^{s}\left(X^{s}\right)$ which also 
violates (16). The equilibrium for country $\mathrm{L}$ which corresponds to $\mathrm{A}$, must lie strictly within the segment $\mathrm{DD}^{\prime}$ in Figure II. The large country will continue to enjoy a larger market share $\left(\sigma^{l}>\sigma^{s}\right)$ but will produce a lower ratio of $X / Y$ than w111 be produced by country $s\left(X^{l} / Y^{l}<X^{s} / Y^{s}\right)$.

This result, together with the assumption of identical homothetic demand between countries implies that the large country will import $X$ in Cournot equilibrium. Such a situation is shown in Figure III, where $A^{l}$ and $A^{s}$ are the autarky equilibria of $\mathrm{L}$ and $\mathrm{S}$ respectively. Given constant returns, the autarky price ratios are equal regardless of size. The trading equilibrium involves country $L$ producing slightly more $X$, then country $S$, but also importing $X$ to reach a final consumption bundle at $c^{\ell} \cdot c^{s}$ shows the corresponding consumption bundle for country $S$.

With differences in country sizes, trade thus equalizes prices, but not marginal rates of transformation $\left(-F^{\ell^{\prime}}\left(X^{b}\right)<-F^{s}\left(X^{s}\right)\right)$. One interesting consequence of this fact in the present model is that trade makes factor prices in the two countries unequal. With constant returns, it is well known that factor prices depend only on marginal rates of transformation. In the absence of trade, our assumptions imply equal MRT and thus equal relative factor prices. Trade leaves the MRT lower in country $L$ and thus makes relative factor prices unequal. By the Stolper-Samuelson relation, the price of the factor used intensively in the production of the monopolized good will be relatively high in the small country. 
FIGURE III
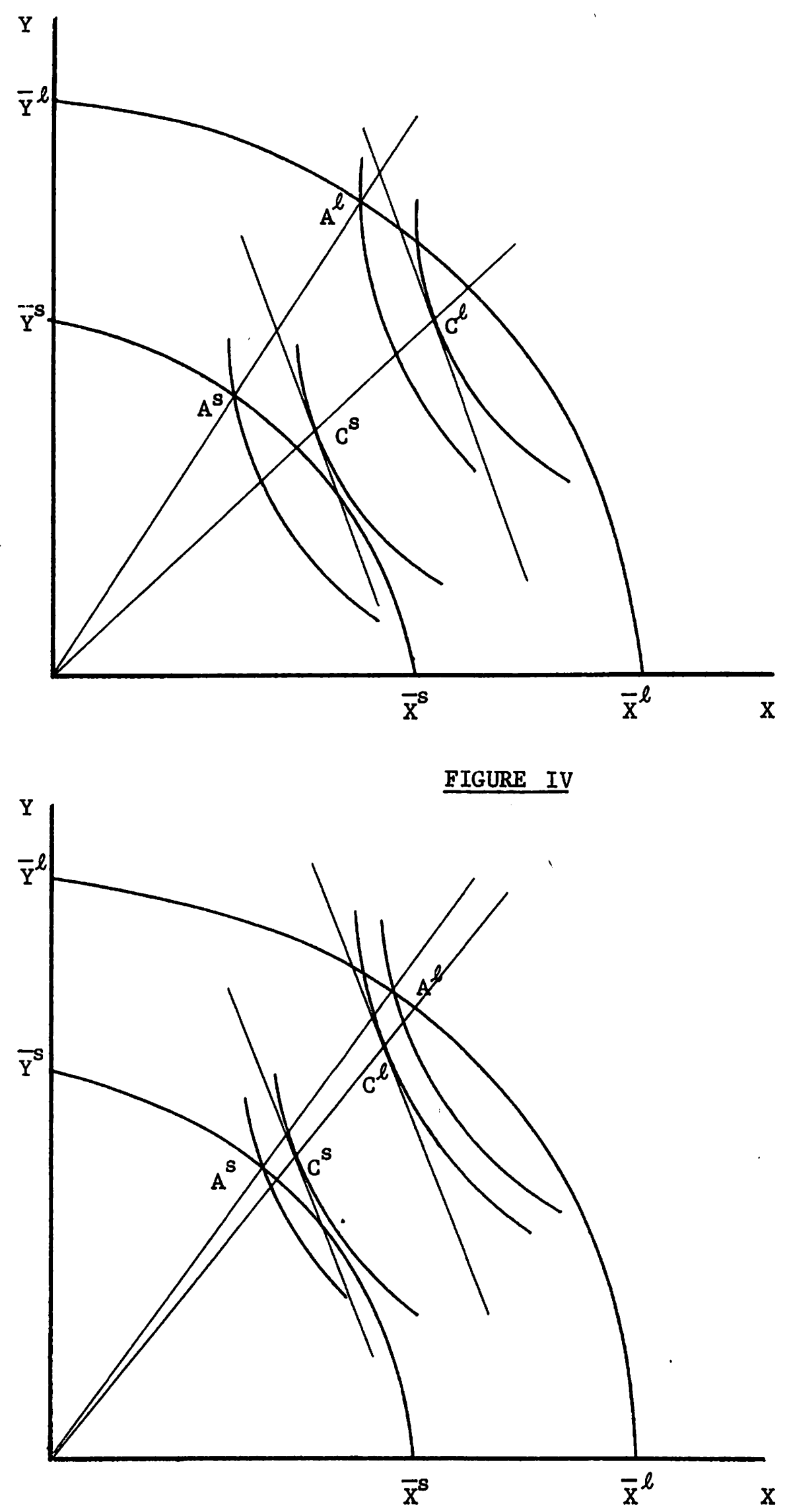
III. The Gains from Trade

The preceding analysis does not demonstrate that trade increases the Income of both countries or even total world real income when countries are of different size. These topics form the subject matter of the present section. Given that production frontlers are concave, it follows that the free trade production bundle, evaluated at the price ratio tangent to the production frontier, is at least as valuable as the autarky production bundle at that same price ratio. From (14) above, this price ratio is $p\left(1-\sigma^{1} / \eta_{x}\right)$ in country 1 . Let subscripts $f$ and a denote free trade and autarky quantities respectively, and let $c_{x}^{1}$ and $c_{y}^{1}$ denote consumption quantities of $X$ and $Y$ in country 1 . The condition on the value of the production bundle can then be written as

$$
\begin{aligned}
& Y_{f}^{1}+p_{f}\left(1-\sigma^{1} / \eta_{x}\right) x_{f}^{1} \geq y_{a}^{1}+p_{f}\left(1-\sigma^{1} / \eta_{x}\right) x_{a}^{1} \quad 1=l, s \\
& Y_{a}^{i}=c_{a y}^{1}, x_{a}^{1}=c_{a x}^{1} ; y_{f}^{1}+p_{f} x_{f}^{1}=c_{f y}^{1}+p_{f} c_{f x}^{1}
\end{aligned}
$$

The second line of (17) simply notes that economy must satisfy a balance of payments constraint when trading and that in autarky, supply must equal demand for each commodity. Substituting these constraints into the first equation of (17), we have

$$
\left[c_{f y}^{1}+p_{f} c_{f x}^{1}\right] \geq\left[c_{a y}^{1}+p_{f} c_{a x}^{1}\right]+p_{f}\left(\sigma^{1} / \eta_{x}\right)\left(x_{f}^{1}-x_{a}^{1}\right)
$$

Equation (18) states that the free trade consumption bundle will be "revealed preferred" to the autarky, consumption bundle if (but not only if) the free trade production of the monopolized good exceeds the autarky production $\left(x_{f}^{i}>x_{a}^{i}\right)$

As will be demonstrated below, Figures III and IV show two of the three possible outcomes given constant returns to scale. In all cases, trade Increases the production of $X$ in country $S$, and hence $S$ always gains from trade. 
Country I may gain as shown In Figure III or may lose when trade decreases the production of $\mathrm{X}$ as shown in Figure IV. The third possibility (not shown) is that country $L$ may experience an increase in welfare despite a decrease in the output of $x$.

The change in total world real income can be analyzed by simply summing the two equations in (18). This shows that a sufficient condition for trade to increase total world real income 18 that free trade production of $X$ exceed autarky production $\left(x_{f}^{\ell}+x_{f}^{8}\right)>\left(x_{a}^{\ell}+x_{a}^{8}\right)$. Such an Increase will in fact always occur given constant returns to scale.

These results can be demonstrated by constructing reaction functions for countries $L$ and $S$ as in Figures $V$ and $V I$. In each diagram point $A$ gives the autarky production levels. The $45^{\circ}$ line a $a^{\prime}$ through point A gives all production points yielding the same total world output as A. It follows from the preceding paragraph that any trading equilibrium above aa' ylelds a total world real income in excess of world income at the autarky equilibria. Any point to the northeast of A implies gains from trade for both countrles. $\ell \ell^{\prime}$ and $88^{\prime}$ in Figures $V$ and VI are the cournot reaction curves of countries $L$ and $S$ respectively. These curves give the duopolist's optimal output of $X$ given the current output of the other duopolist. Consider first the point $l^{\prime}$ which gives $L^{\prime} s$ output of $X$ in a trading situation when $S$ produces no $x$. It is easy to show that $\ell^{\prime}$ must lie between $x_{a}^{l}$ and $a^{\prime}$. At $x_{a}^{l}$, $s$ is specialized in the production of $Y$. Thus marginal revenue for $L$ must now be higher than in the absence of trade, since, the aggregate production ratio $(\mathrm{X} / \mathrm{Y})$ is now lower (recall that this ratio determines marginal revenue). At $a^{\prime}$, marginal cost will be higher (concavity of the production frontier) and marg Inal revenue will be lower than in autarky. This latter effect occurs because with the world production of $x$ unchanged $\left(x_{f}^{\ell}=x_{a}^{\ell}+x_{a}^{8}\right)$ the world production of $\mathrm{Y}$ must be lower. This is due to the inefficlency introduced by having the two countries producing at different MRT. 


\section{FIGURE V}

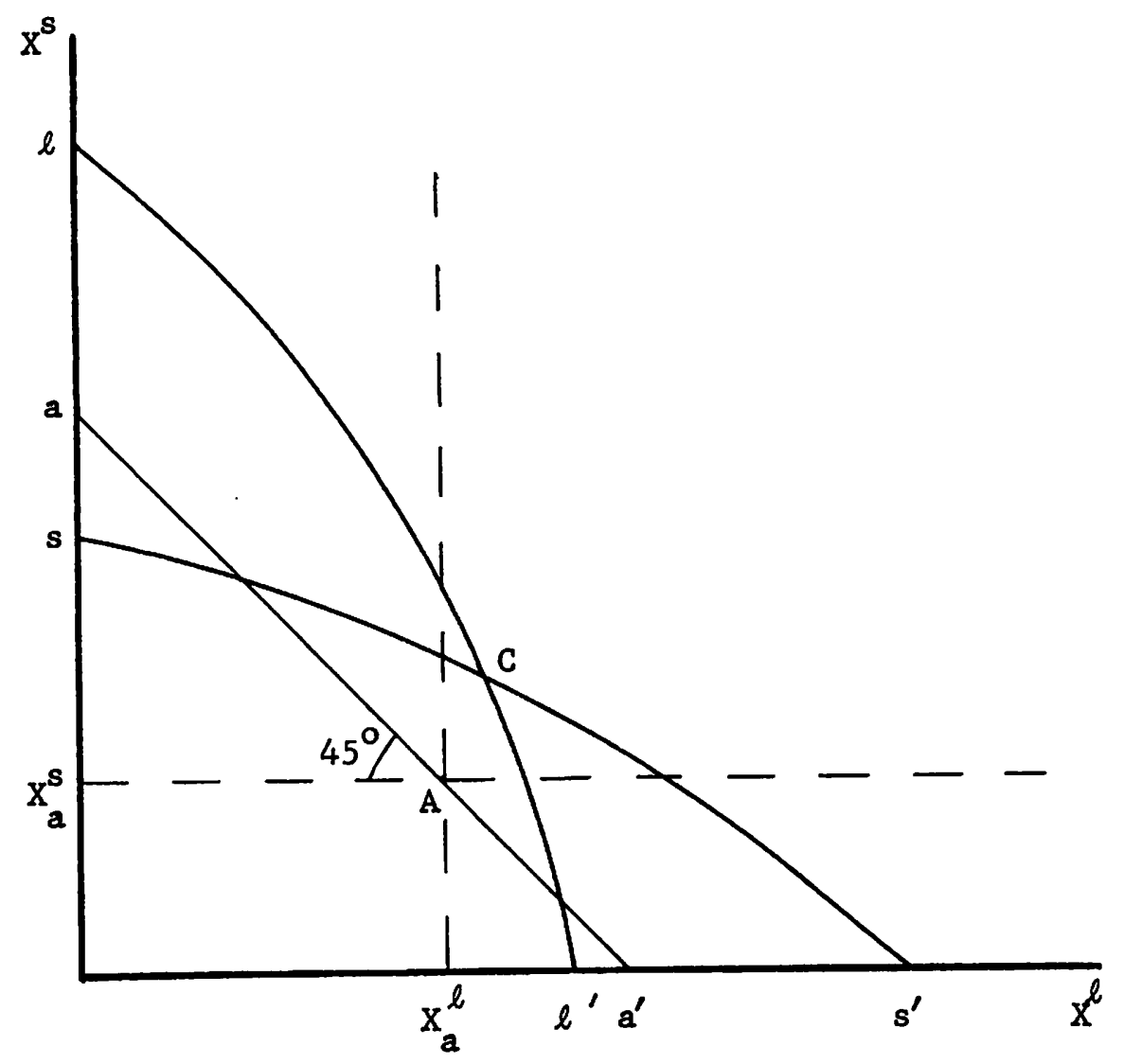

FIGURE VI

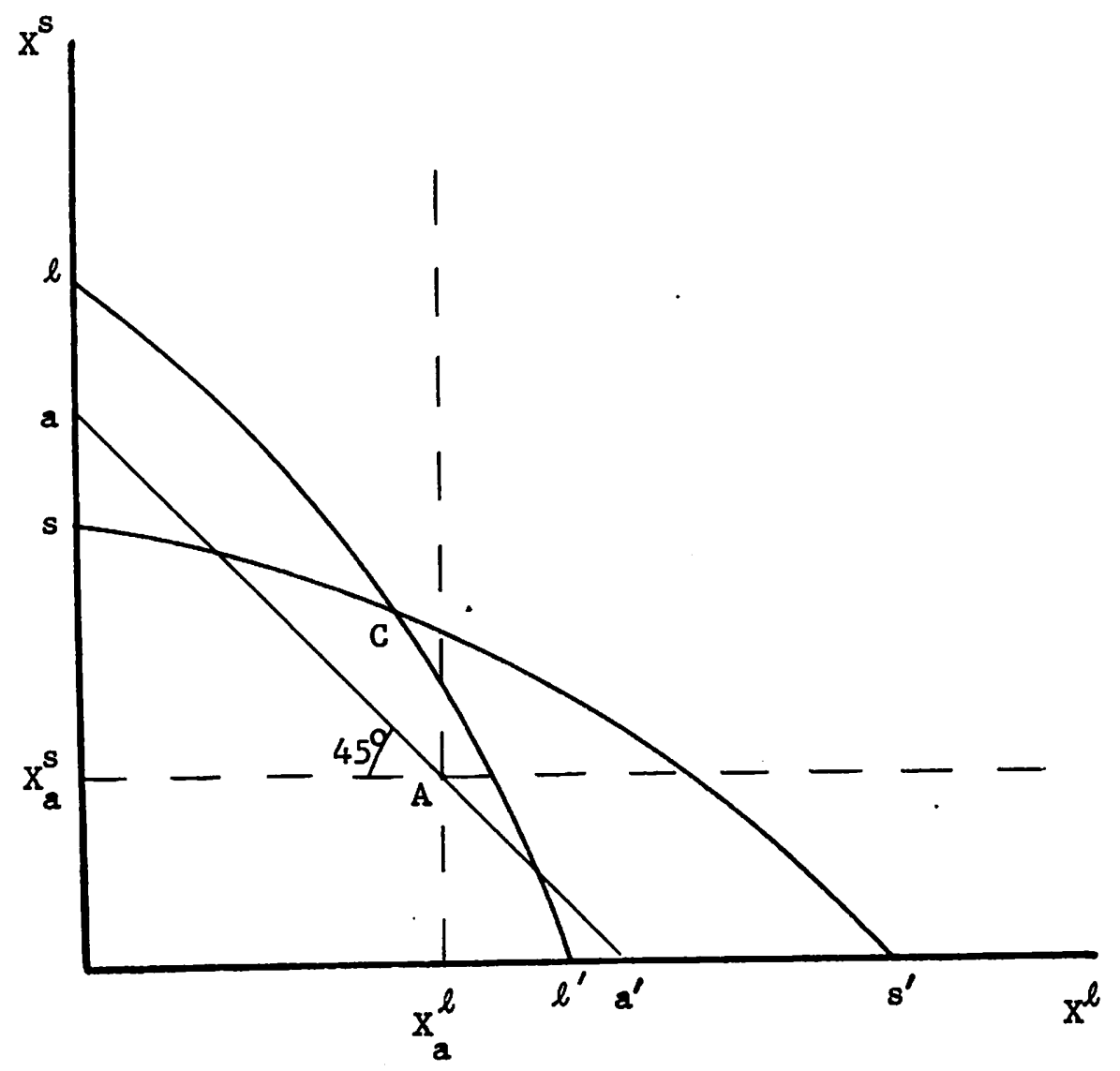


A second property of $l \ell^{\prime}$ in Figures $V$ and VI is that it must pass to the right of $A$. With trade at $A, \eta_{x}$ and $M C_{x}$ are the same as in the absence of trade, but marginal revenue must be higher due to L's lower market share. Thus $L$ should expand production given $x^{8}=x_{a}^{8}$.

A similar argument will show that $s$ lies between $a$ and $x_{2}^{s}$ in Figures $V$ and $V I$, and that $\mathbf{s s}^{\prime}$ must pass above point $A$.

The slopes of $\ell \ell^{\prime}$ and $8 s^{\prime}$ can be found by using the first-order condition for the monopolist in each country. Denoting profit as $\pi^{1}$, these are given by

$$
\frac{d \pi^{\ell}}{d x^{\ell}}=p+x^{\ell} \frac{d p}{d x^{\ell}}-c^{\ell^{\prime}}\left(x^{l}\right)=0
$$

$$
\frac{d \pi^{8}}{d x^{8}}=p+x^{8} \frac{d p}{d x^{8}}-c^{8^{\prime}}\left(x^{8}\right)=0
$$

Differentiation of (19) and (20) gives us the following.

$$
\begin{aligned}
d\left(\frac{d \pi^{\ell}}{d x^{\ell}}\right) & =2 \frac{d p}{d x^{\ell}} d x^{\ell}+\frac{d p}{d x^{8}} d x^{8}+x^{\ell} \frac{d^{2} p}{d x^{\ell 2}} d x^{\ell} \\
& +x^{\ell} \frac{d^{2} p}{d x^{l} d x^{8}} d x^{8}-c^{\ell^{\prime \prime}}\left(x^{l}\right) d x^{\ell}=0 \\
d\left(\frac{d \pi^{8}}{d x^{8}}\right) & =2 \frac{d p}{d x^{8}} d x^{8}+\frac{d p}{d x^{\ell}} d x^{\ell}+x^{8} \frac{d^{2} p}{d x^{82}} d x^{8} \\
& +x^{8} \frac{d^{2} p}{d x^{\ell} d x^{8}} d x^{\ell}-c^{8}\left(x^{8}\right) d x^{8}=0
\end{aligned}
$$

All first derivatives of $p$ with respect to $x^{\ell}$ and $x^{s}$ are equal as are all second derivatives since $p$ is a function of the sum of $x^{l}$ and $x^{s}$. Dropping the superscripts, the signs of the derlvatives in.(21) and (22) are given as follows. 
(23)

$$
d p / d x^{1}=d p / d x<0, d^{2} p / d x^{1} d x^{j}=d^{2} p / d x^{2},\left[2 \frac{d p}{d x}+x^{1} \frac{d^{2} p}{d x^{2}}\right]<0 .
$$

The signs in (23) follow from earlier restrictions guaranteeing diminishing marginal revenue. $C^{i / \prime}>0$ in $(21)$ and (22) by virtue of increasing marginal cost (concavity of the production frontier).

Equations (21) and (22) give us the slopes of the reaction curves for $L$ and $S$ respectively.

$$
\begin{aligned}
& \left.\left[\frac{d x^{8}}{d x^{l}}\right]^{\ell}=-\frac{\left[2 \frac{d p}{d x}+x^{\ell} \frac{d^{2} p}{d x^{2}}\right]-c^{\ell^{\prime \prime}}\left(x^{l}\right)}{\left[\frac{d p}{d x}+x^{\ell} \frac{d^{2} p}{d x^{2}}\right]} \quad \text { (Slope of } l l^{\prime}\right) \\
& {\left[\frac{d x^{8}}{d x^{\ell}}\right]=-\frac{\left[\frac{d p}{d x}+x^{8} \frac{d^{2} p}{d x^{2}}\right]}{\left[2 \frac{d p}{d x}+x^{8} \frac{d^{2} p}{d x^{2}}\right]-c^{s^{\prime \prime}}\left(x^{8}\right)} \quad \text { (Slope of ss') }}
\end{aligned}
$$

Combining (24) and (25) with (23), we have

$$
\left[\frac{d x^{8}}{d x^{\ell}}\right]^{\ell}<-1,-1<\left[\frac{d x^{8}}{d x^{\ell}}\right]^{8}<0 .
$$

Equation (26) notes that $l \ell^{\prime}$ must be everywhere steeper than $a a^{\prime}$ (the $45^{\circ}$ Iine) in Figures $V$ and $V I$, and notes that $88^{\prime}$ must be everywhere flatter than $a a^{\prime}$. These two results, combined with the facts that $l f^{\prime}$ passes to the right of $A$, and $88^{\prime}$ passes above $A$, are sufficlent to guarantee that $l l^{\prime}$ and $88^{\prime}$ intersect exactly once and that this intersection occurs above a a' as shown In Figures $V$ and VI (point $C$ ). It follows in turn from equation (18) that world real income must be higher at the Cournot equilibrium than in autarky. Previous results allow us to place one additional restriction on $C$. It follows from the discussion of Figure II and from earlier assumptions underlying that analysis (e.g., constant returns), that country I must have 
a lower relative market share in Cournot equilibrium than it had in autarky, Implying that $\left(x_{f}^{\ell} / x_{f}^{8}\right)<\left(x_{a}^{\ell} / x_{a}^{s}\right)$. It then follows that polnt $C$ in Figures $V$ and VI must lie above a ray from the origin through point A. Combined with the result of the previous paragraph, this ensures us that $x_{f}^{8}>x_{a}^{8}$ and thas that country S unambiguously gains from trade (equation 19).

Two situations can occur with respect to country $L . x_{f}^{l}>x_{a}^{l}$ as in Figure $V$, or $x_{f}^{\ell}<x_{a}^{\ell}$ as in Figure VI. In the former case, country $L$ unambiguously gains. In the latter case, country I may gain or may lose (Figure VI). 
IV. Increasing Returns to Scale

One motivation for assuming monopoly in the production of $\mathrm{X}$ is that there are increasing returns to scale in the $\mathrm{X}$ industry. I held off introducing this assumption, however, in order that we could clearly distinguish effects due to monopoly power per se from those due to a combination of increasing returns and monopoly power. In this section, I will show that many, but not all of the results derived in the previous two sections continue to hold with increasing returns. Throughout this section, we will continue to assume identical relative factor endowments in order to avoid the complications of Heckscher-Ohlin effects.

Previous papers have shown that increasing returns introduces two complications. First, the production frontier may by convex (the production set may be non-convex) (Herberg and Kemp (1969), Melvin (1969), Chipman (1970)). This result always occurs if, for example, there are no differences in factor intensities between industries such that the constant returns production frontier is linear. Second, the MRT in the large country will be less than the MRT in the small country at any given output ratio $\mathrm{Y} / \mathrm{X}$, given increasing returns in $X$ and constant returns in $Y$ (Markusen and Melvin (1980)). In terms of Figure II, the MRT will be less at $D^{\prime}$ than at A.

When two countries are absolutely identical in all respects as in Figure I, the second complication is obviously irrelevant. Non-convexity of the production set is also irrelevant for the question of the existence of equilibrium (Markusen (1980)). There will continue to exist a CournotNash equilibrium in which each country produces an identical bundle characterized by $x_{f}^{i}>x_{a}^{i}$, such that the welfare of each country is improved as in Figure I. This equilibrium may, however, be unstable, and may lead to production at an alternate equilibrium in which one or both countries is specialized. An analysis of this stability question is temporarily postponed. 
Consider now the case in which countries are of different size, but in which returns to scale are insufficiently strong to cause non-convexities in the production set. In this situation most of the properties of the reaction curves derived in the preceding section remain valid, The reason is that concavity of the production frontier continues to imply that the generalequilibrium marginal cost of $\mathrm{X}$ in terms of $\mathrm{Y}$ is an increasing function of $X\left(C^{\prime \prime}(X)>0\right)$. It follows from the arguments of the preceding section that (A) $\ell^{\prime}$ in Figures $V$ and VI continues to lie between $x_{a}^{l}$ and $a^{\prime}$, (B) the slope of $l l^{\prime}$ is everywhere less than -1 (equation (24)), and (C) $l l^{\prime}$ passes to the right of A. Similar comments apply to $\mathrm{ss}^{\prime}$. It thus remains true that $l \mathrm{l}^{\prime}$ and $s s^{\prime}$ intersect at a unique point above $a a^{\prime}$ in Figures $V$ and $V I$, and that trade necessarily increases total real world income.

The one property of the constant returns case which does not continue to hold is that given in equation (16). With increasing returns, size matters as noted above. Thus (16) must now be amended as follows:

$$
\begin{aligned}
& \sigma^{l}>\sigma^{\dot{s}} \Leftrightarrow-F^{l^{\prime}}\left(X^{l}\right)<-F^{s^{\prime}}\left(X^{s}\right) \\
& X^{l} / Y^{l} \leq X^{\dot{s}} / Y^{s} \Rightarrow-F^{\ell^{\prime}}\left(X^{b}\right)<-F^{s^{\prime}}\left(X^{s}\right)
\end{aligned}
$$

The second line of (27) is no longer an if and only if relation. With the MRT in $\mathrm{L}$ flatter along any ray from the origin, it is now possible that $\sigma^{\ell}>\sigma^{\dot{s}}$ and $\left(x^{l} / Y^{l}>X^{8} / Y^{s}\right)$. Due to cost advantage in the production of $X$, it can now be the case that country $L$ exports $X$ in Cournot equilibrium. This is not an inevitable outcome, but it becomes more likely the higher the degree of returns to scale. This result implies that country $S$ can now lose from trade when it is the importer of $X$ (equation (10)). In terms of Figures $V$ and VI, cournot equilibrium may now lie below $x_{a}^{s}$. The result of the previous section must be weakened somewhat to state that trade necessarily increases total world real 
income, but may lead to a deterioration in welfare for the country importing $\mathrm{X}$. Consider now the case where increasing returns dominate differences in factor intensities such that $C^{\prime \prime}<0$ (the production frontier is convex). This implies that $l^{\prime}$ must lie to the right of $a^{\prime}$ in Figures $V$ and VI. At $a^{\prime}$, MC for $L$ is lower than at $x_{a}^{l}$ and marginal revenue is higher than in autarky. This latter effect occurs since with total production of $\mathrm{X}$ the same as in autarky, the total production of $\mathrm{Y}$ must be greater than in autarky due to decreasing costs (see Melvin (1969)),$\left(\mathrm{X}_{f} / \mathrm{Y}_{f}\right)<\left(\mathrm{X}_{a} / \mathrm{Y}_{\mathrm{a}}\right)$ implies higher marginal revenue as noted earlier. Thus $l^{\prime}$ lies to the right of $a^{\prime}$ and $s$ lies above $a$ by $a$ similar argument.

It remains true in the present case that $l l^{\prime}$ must pass to the right of $A$ and that $s^{\prime}$ 'must pass above $A$ as in Figures $V$ and $V I$. At $A$, the lower market share of each duopolist relative to his autarky share of 1 , gives each an incentive to expand output holding the other duopolist's output constant.

The principal problem lies in the fact that the sign restrictions given in (26) may no longer be valid. Second order conditions imply that both reaction curves continue to be downward sloping, but the fact that $\mathrm{c}^{\prime \prime}<0$ may mean that one or both of the restrictions in (26) no longer holds. In particular, we have

$$
\begin{aligned}
& c^{\ell^{\prime \prime}}<0,\left|c^{\ell^{\prime \prime}}\right|>\left|\frac{d p}{d x}\right| \Rightarrow-1<\left[\frac{d x^{s}}{d x^{\ell}}\right]^{\ell}<0 \\
& c^{s^{\prime \prime}}<0,\left|c^{s^{\prime \prime}}\right|>\left|\frac{d p}{d x}\right| \Rightarrow\left[\frac{d x^{s}}{d x^{l}}\right]^{s}<-1 .
\end{aligned}
$$

Note from (28) and (29) that $C^{i^{\prime \prime}}<0$ is a necessary, but not a sufficient condition for the restriction on $i$ 's reaction function in (26) to be invalid. It is probably apparent from (28) and (29) that all sorts of outcomes are possible, and I do not particularily want to get into a taxonomy of these possibilities. Perhaps, therefore, I can simply indicate what the important results are. 
First, if both sign restrictions in (26) remain everywhere valid in spite of convex production frontiers, then $l \ell^{\prime}$ and $\mathrm{ss}^{\prime}$ continue to cross above $\mathrm{aa}^{\prime}$ in Figures $\mathrm{V}$ and VI. However, this does not guarantee that trade increases world real income since equation (17) is no longer valid (Kemp (1970)). In fact, the signs of (17) and (18) are reversed if both countries remain diversified in production. Diversification is ensured by (26) and by the facts that $l l^{\prime}$ passes to the right of $A$ and $s s^{\prime}$ passes above $A$. From Kemp, (18) becomes

$$
\left[c_{f y}^{i}+p_{f} c_{f x}^{i}\right] \leq\left[c_{a y}^{i}+p_{f} c_{a x}^{i}\right]+p_{f}\left(\sigma^{i} / \eta_{x}\right)\left(x_{f}^{i}-x_{a}^{i}\right)
$$

Equation (30) implies that expansion of world output of $X$ is now a necessary but not a sufficient condition for trade to increase world real income. 4 Similarly, expansion in the domestic production of $X$ is now a necessary condition for countries to gain individually. The country which imports $\mathrm{X}$ is now definitely a loser.

Second, consider the case in which both sign restrictions in (26) are everywhere violated (i.e., (28) and (29) hold). Since it remains true that $l l^{\prime}$ passes to the right of $A$ and $s s^{\prime}$ passes above $A$, it follows that $l \ell^{\prime}$ and $s s^{\prime}$ now cross in the opposite direction to that indicated in Figures V and VI. Indeed, we can depicit two of many possible cases by simply switching the labels $l l^{\prime}$ and ss ' in Figures $V$ and VI. $l l^{\prime}$ and ss ' may intersect either inside or outside of aa' or may not intersect at all. The important point however is that any interior intersection is unstable given $l l^{\prime}$ and $s \dot{s}^{\prime}$ must cross in this manner (i.e., $\ell l^{\prime}$ flatter than $s s^{\prime}$ ). At a point on $l l^{\prime}$ to the right of $C$, for example, $S$ will reduce output, followed by an increase by $L$, followed by a further decrease by $S$, etc., until point $l^{\prime}$ is reached. 
$\ell^{\prime}$ and $s^{\prime}$ will be stable equilibria, in which the total production of $\mathrm{X}$ exceeds total autarky production (recall $l^{\prime}$ lies to the right of $a^{\prime}$ and $s$ lies above a in this case). Either stable equilibria involves an increase in total world real income relative to autarky. To show this, first consider point $a^{\prime}$, which is Pareto superior to point $A$ in Figures $V$ and VI. At $a^{\prime}$, total production of $X$ equals that at $A$, but total production of $Y$ is greater than at A due to decreasing costs. But although $a^{\prime}$ is Pareto superior to $A$, it is not Pareto optimal since $p>M R>M C$. Any increase in $\mathrm{x}^{\ell}$ above $\mathrm{a}^{\prime}$ increases welfare up to the point where $\mathrm{p}=\mathrm{MC}$. $\ell^{\prime}$ stops short of this equality, but is nevertheless Pareto superior to $a^{\prime}$, and thus to A. Similar comments apply to point $s$ in Figures $V$ and VI. Thus either stable equilibria involves an increase in world real income relative to autarky. Once again, however, one of the countries may lose. ${ }^{6}$ Interested readers are referred to Kemp (1970), Melvin (1969), or Markusen and Melvin (1980) for a more complete discussion of trading equilibria with nonconvex production sets.

V. Summary and Conclusions

(1) The purposes of this paper were to show how imperfect competition can form a basis for trade, and to show the distribution of gains (or losses) from trade under this assumption. A two-good, two-country model was constructed in which the production of one good was monopolized in each country (i.e., the same good was monopolized in each country). Under the assumption of cournotNash behavior, it was demonstrated that trade will lead to a bilateral welfare improvement when countries are Identical in all respects. Trade doubles the size of the market relative to autarky and doubles the number of producers. If each duopolist continued to produce his autarky output, he would now find 
that perceived marginal revenue is greater than marginal cost. Thus trade leads each duopolist to increase his output, resulting in bilateral welfare improvements. This finding is similar to the findings of Melvin (1969) and Krugman (1979) who note that increasing returns to scale may Imply gains from trade even if countries are identical in all respects.

(2) With constant returns to scale in production, but countries differing in size, it was shown that Cournot-Nash equilibrium will involve the large country importing the monopolized good. World real income will definitely increase with trade as will the real income of the smaller country. The monopolist in the large country may however reduce production relative to autarky which could possibly result in negative gains from trade for the large country. A second interesting result in this case is that trade makes factor prices between countries unequal. With constant returns and identical relative factor endowments, factor prices are equalized in autarky. At the Cournot equilibrium, the price of the factor used intensively in the production of monopolized good is relatively high in the large country.

(3) With "weakly" increasing returns (1.e., the production frontier is concave), it remains true that trade must increase world real income relative to autarky. However, the large country will now have a cost advantage in the production of the monopolized good which works in the opposite direction to the country size effect just mentioned. The result is that the direction of trade is indeterminate in the general case. The country which does export the monopolized good in Cournot-Nash equilibrium will always gain while the importer may or may not gain as in the constant returns case. 
(4) A complication introduced by "strongly" increasing returns (i.e., the production frontier is convex) is that total world real income can fall with trade, provided that both countries are diversified in production at the Cournot-Nash equilibrium. In this situation, expansion in the domestic production of the monopolized good becomes a necessary rather than a sufficlent condition for the country to gain from trade. This finding is similar to a result by Kemp (1970) for the case of externality-induced convexity of the production frontier.

(5) A final result was to show that with strongly increasing returns, the Cournot-Nash equilibrium with both countries diversified may be unstable. Alternate stable equilibria in which only one country produces the monopolized good necessarily involve an increase in total world real income relative to autarky, but do not necessarily involve gains for both countrles. 


\section{Footnotes}

${ }^{1}$ Kindleberger (1969) makes a similar point in discussing foreign investment flows rather than trade flows. Direct foreign investment may have a very important impact on a small country's welfare via reducing the market power of domestic monopolies.

2 Markusen and Melvin (1980) note a similar result in the presence of increasing returns to scale: reductions in tariffs or transport costs between countries may make factor prices more unequal.

$3_{\sigma}^{l}$ is sometimes known as country L's "conjectural variation". For behavioral assumptions other than the Cournot assumption used here, conjectural variations are not in general equal to market shares.

4

4 The reader can see this result by constructing a simple diagram with a convex production frontier. Draw a tangent to any point on the production frontier (call it point A) and a line with the same slope as the original tangent through any other point (call it point $B$ ). At the price ratio given by the tangent to $A$, the value of income at $A$ is clearly lower than the value of income at $B$. The opposite relation between $A$ and $B$ occurs if the production frontier is concave. Hence (18) and (30) have opposite signs.

5 When countries are identical in all respects such that no trade takes place at the Cournot equilibrium, expansion in the domestic production of $X$ remains a sufficient condition for an improvement in domestic welfare. The reader can see this by constructing a diagram as in the previous footnote, and by constructing the equilibria points $A$ and $C$ in Figure $I$ on the new diagram. It will be apparent that welfare at $C$ (the trading equilibria) will be higher than at $A$ (the autarky equilibria) even though production at $C$ evaluated at the price ratio tangent to $c\left(p_{f}\left(1-\sigma^{i} / \eta_{x}\right)\right)$ is less than the value of production at $A$ at that same price ratio.

${ }^{6}$ Instability of the diversified equilibrium can also occur when both countries are of identical size. In this case, any of the equilibria, $C, \ell^{\prime}$ or $s$ are Pareto superior to $A$, and $\ell^{\prime}$ and $s$ are in turn Pareto superior to $C$. 


\section{References}

Chipman, John, "External Economies of Scale and Competitive Equilibrium," Quarterly Journal of Economics 84 (1970), 347-363.

Ethier, Wilfred, "Internationally Decreasing Costs and World Trade," Journal of Internationa1 Economics 9 (1979), 1-24.

Graham, Frank, "Some Aspects of Protection Further Considered," Quarterly Journal of Economics 37 (1923).

Herberg, Horst, and Murray Kemp, "Some Implications of Variable Returns to Scale," Canadian Journal of Economics 3 (1969), 403-415.

Herberg, Horst, and Murray Kemp, "Factor Market Distortions, the Shape of the Locus of Competitive Outputs, and the Relation between Product Prices and Equilibrium Prices," in Bhagwati et. al., Trade, Balance of Payments and Growth, North Holland (1971).

Kemp, Murray, The Pure Theory of International Trade and Investment, PrenticeHa11 (1970), 154-179.

Kindleberger, Charles, American Business Abroad, Yale University Press (1969), 1-36. Reprinted in Baldwin and Richardson (editors), International Trade and Finance, Little Brown (1974), 267-284.

Krugman, Paul, "Increasing Returns, Monopolistic Competition, and International Trade," Journal of International Economics 9 (1979), 469-480.

Markusen, James, "Simple General Equilibrium with a Monopolized Sector: A Comparison of Alternate Specifications," University of Western Ontario Working Paper (1980).

Markusen, James and James Melvin, "Trade, Factor Prices, and the Gains from Trade with Increasing Returns to Scale," University of Western Ontario Working Paper (1980). 
Markusen, James and Arthur Robson, "Simple General Equilibrium and Trade with a Monopsonized Sector," University of Western Ontario.Working Paper (1980). Melvin, James, "Increasing Returns to Scale as a Determinant of Trade," Canadian Journal of Economics 3 (1969), 389-402.

Melvin, James and Robert Warne, "Monopoly and the Theory of International Trade," Journal of International Economics 3 (1973), 117-134.

Negishi, Takashi, "Monopolistic Competition and General Equilibrium," Review of Economics and Statistics 28 (1961), 196-201.

Ohlin, Bertil, Interregional and International Trade, Harvard University Press (1933). 
CENTRE FOR THE STUDY OF INTERNATIONAL ECONOMIC RETLATIONS

$$
\begin{gathered}
\text { University of Western Ontario } \\
\text { Working Papers }
\end{gathered}
$$

8001. Robson, Arthur J. OPEC VERSUS THE WEST: A ROBUST DUOPOLY SITUATION

8002. McMillan, John and Ewen McCann. WELFARE EFFECTS IN CUSTOMS UNIONS

8003. Leith, J. Clark. MONEY, THE BALANCE OF PAYMENTS, AND GOVEPNMENT DEBT IN A SMALL OPEN LDC: . HAITI

8004. Mansur, Ashan and John Whalley. A DECOMPOSITION ALCORITHM FOR GENERAL EQUILIBRIUM COMPUTATION WITH APPLICATION TO INIERNATIONAL TRADE MODELS

8005. Schmid, Michael. OIL, EMPLOYMENT AND THE PRICE IEVEL: A MONETARY APPROACH TO THE MACROECONOMICS OF IMPORIED INTERMEDIATE COODS UNDER FIXED AND FLEXIBLE RATES

8006. Markusen, James R. THE DISTRIBUTION OF GAINS FROM BIIATERAL TARIFF REDUCTION 8007. Markusen, James R. TRADE AND THE GAINS FROM TRADE WITH IMPERFECT COMPETITION 8008. Markusen, James R. and James R. Melvin. TRADE, FACTOR PRICES, AND THE GAINS FROM TRADE WITH INCREASING RETURNS TO SCALE 